Fournal of Medical Genetics (1973). 10, 333.

\title{
The Relation of Sex of Affected Parent to the Age at Onset of Huntington's Disease
}

\author{
C. J. BRACKENRIDGE \\ Department of Psychiatry, University of Melbourne, Victoria, Australia
}

\begin{abstract}
Summary. Subjects affected with Huntington's disease were ascertained from the literature and their sex, age at onset of symptoms, major neurological sign (choreo-athetosis or rigidity), and sex of affected parent were recorded. The onset ages of 130 rigid subjects had a lognormal distribution, while those of 434 choreic subjects were normally distributed.

Regression analysis indicated that there was an inverse relation between paternal descent and the logarithm of the onset age of rigid persons. It was shown that the well-known predominance of paternal cases of early onset is an extrapolation from adulthood of a general effect. No such relation was found for choreic subjects. It is concluded that there are no genetic reasons to support the idea of a distinct juvenile variant of the disorder.
\end{abstract}

According to a widely accepted classification of Huntington's disease, the choreic form described so lucidly by Huntington (1872) is differentiated from the Westphal or rigid form in which a Parkinsonian picture predominates. Cases of early onset make up a third form, the juvenile variant, in which either choreic or, more usually, rigid features appear before adulthood. This form is the most difficult to define precisely, and current usage assigns all childhood and adolescent patients to this category. Myrianthopoulos (1966) has drawn attention to the high frequency of epileptic seizures observed in young subjects and Bruyn (1968) has emphasized the excess of paternal cases, a fact first reported by Merritt et al (1969). The conclusion by Jones and Phillips (1970) that there is no general shift towards early onset in cases of paternal descent suggests that an excess of paternal patients is a hallmark of the juvenile form. This is supported by the observation of an equal sex ratio among affected parents of adult rigid subjects (Bruyn, 1969).

The present study represents an attempt to delineate the so-called juvenile variant more clearly by examining the affected parentage of rigid and choreic patients over the complete age range.

\section{Material and Methods}

Subjects affected with Huntington's disease were

Received 10 May 1973. ascertained from the literature if their sex, age at onset of symptoms, predominant neurological sign (choreoathetosis or muscular rigidity), and sex of affected parent were known. The sources used were those cited in Appendix III of Brackenridge (1972).

The null hypothesis formulated was that age at onset is unrelated to sex of affected parent and neurological sign. A multiple regression model involving age at onset as the dependent variable was considered to be the most appropriate statistical test of the hypothesis; this would enable any effects of the independent variables to be observed over the whole age range. If a distinct juvenile form of the disease exists, a change in gradient might be anticipated near late adolescence or early adulthood.

Non-parametric tests were carried out as described by Sokal and Rohlf (1969).

\section{Results}

The onset ages of the 564 ascertained subjects with Huntington's disease were distributed asymmetrically. Because of the requirements of the regression model, it was necessary for the dependent variable to be normally distributed. The sample was therefore divided into rigid and choreic subjects and the two distributions are shown in Fig. 1. Kolmogorov-Smirnov tests of goodness-of-fit indicated that the onset ages of the 130 rigid persons had a lognormal distribution $(\mathrm{D}=0.068, \mathrm{p}>0.6)$ and that the onset ages of the 434 choreic persons were normally distributed $(\mathrm{D}=0.051, \mathrm{p}>0.2)$. As 


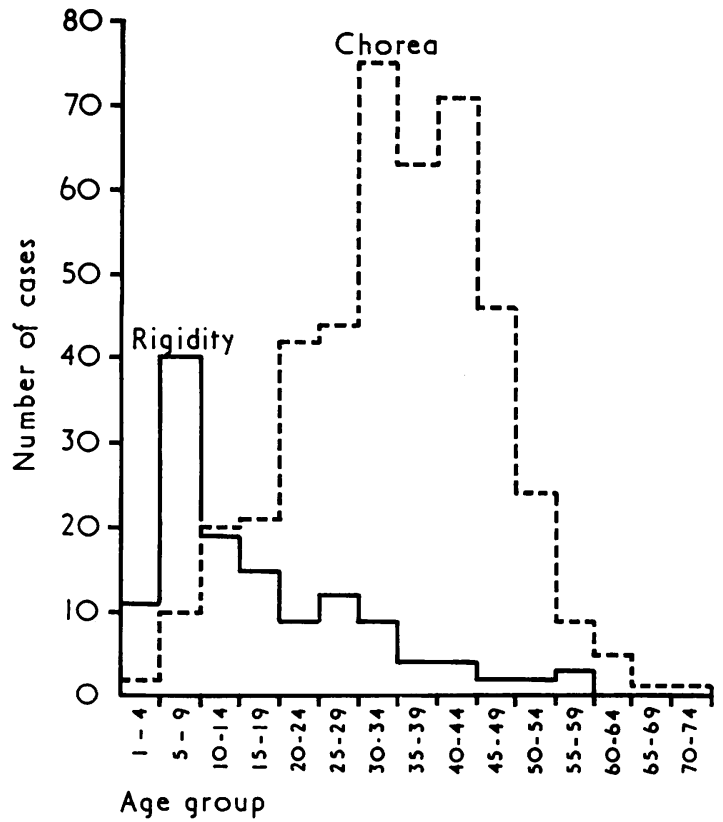

FIG. 1. Frequency distributions of the onset ages of 130 rigid and 434 choreic subjects.

would be expected from a visual inspection of the two distributions, Kruskal-Wallis tests revealed that rigid subjects were significantly younger than choreic subjects when symptoms first appeared. The arithmetic means and standard deviations of the onset ages were $18.0 \pm 17 \cdot 2$ years for rigidity (estimated according to Finney, 1941) and 33.9 \pm 12.1 years for chorea.

Multiple regression equations were set up using sex of subject and sex of affected parent as independent dummy variables, 0 representing males and 1 representing females. The equation for rigidity involved the logarithm of onset age as dependent variable, while the equation for chorea used unaltered ages. Stepwise analysis demonstrated that parental sex, although contributing only $4 \cdot 7 \%$ to the reduction of sum of squares for rigidity, possessed a significant regression coefficient of $0.388 \pm$ $0.155(p<0.02)$. Sex of subject was not a significant variable. For chorea, neither variable was a significant determinant of age at onset. It follows that onset age is directly related to the proportion of maternal cases with rigidity but not with chorea.

Inspection of the grouped data presented in Table I reveals the decreasing proportions of paternal rigid subjects as their onset ages increase. There is a less marked trend in this direction in the data for choreic cases in Table II. Parenthetically, it is interesting to note that the excess of paternal cases

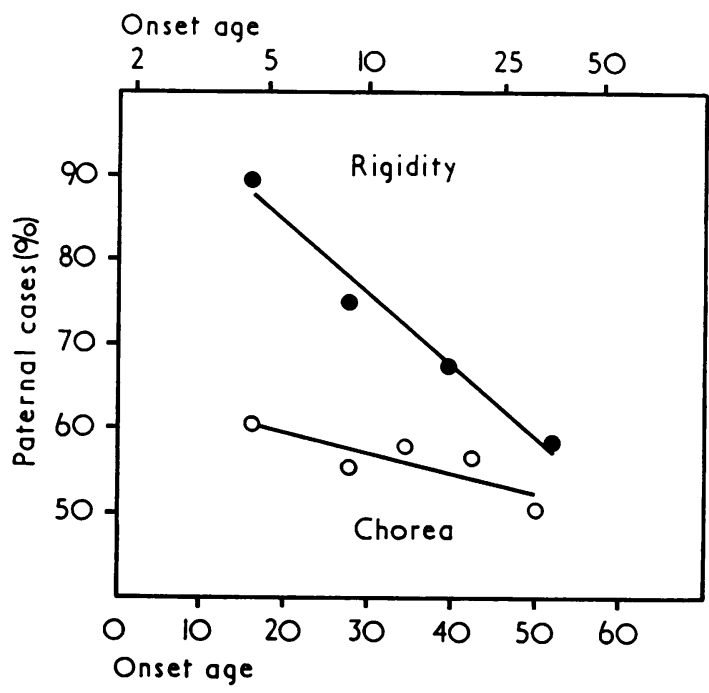

Fig. 2. The linear regression of percentage of paternal cases on (above) the logarithm of onset ages of rigid subjects and (below) the onset ages of choreic subjects.

in rigidity $(2.51: 1)$ is almost double that found for chorea (1.28:1); the difference is significant at the $0.5 \%$ level $\left(\chi^{2}=9 \cdot 13\right.$, corrected for continuity). The analysis in Table III of the grouped data confirms the effect of parental sex on rigid cases indicated by multiple regression.

It remained to show that the well-known predominance of paternal cases of early onset is an extension of this general effect. The absence of any

TABLE I

RELATION OF PROPORTION OF RIGID CASES OF PATERNAL DESCENT TO AGE AT ONSET

\begin{tabular}{c|c|c|c|c}
\hline $\begin{array}{c}\text { Onset Age } \\
\text { (Range) }\end{array}$ & $\begin{array}{c}\text { Paternal } \\
\text { Cases }\end{array}$ & $\begin{array}{c}\text { Maternal } \\
\text { Cases }\end{array}$ & Total & $\begin{array}{c}\text { Paternal } \\
\text { Cases (\%) }\end{array}$ \\
\hline $1-6$ & 25 & 3 & 28 & 89 \\
$7-12$ & 24 & 8 & 32 & 75 \\
$13-24$ & 23 & 11 & 34 & 68 \\
$25-59$ & 21 & 15 & 36 & 58 \\
\hline Total & 93 & 37 & 130 & \\
\hline
\end{tabular}

TABLE II

RELATION OF PROPORTION OF CHOREIC CASES OF PATERNAL DESCENT TO AGE AT ONSET

\begin{tabular}{c|c|c|c|c}
\hline $\begin{array}{c}\text { Onset Age } \\
\text { (range) }\end{array}$ & $\begin{array}{c}\text { Paternal } \\
\text { Cases }\end{array}$ & $\begin{array}{c}\text { Maternal } \\
\text { Cases }\end{array}$ & Total & $\begin{array}{c}\text { Paternal } \\
\text { Cases (\%) }\end{array}$ \\
\hline $4-23$ & 52 & 34 & 86 & 60 \\
$24-31$ & 51 & 41 & 92 & 55 \\
$32-38$ & 51 & 37 & 88 & 58 \\
$39-44$ & 47 & 36 & 83 & 57 \\
$45-74$ & 43 & 42 & 85 & 51 \\
\hline Total & 244 & 190 & 434 & \\
\hline
\end{tabular}


TABLE III

TESTS FOR TREND IN THE PARENTAL SEX-DEPENDENCE OF THE ONSET AGES OF RIGID AND CHOREIC SUBJECTS

\begin{tabular}{l|c|c|c|c|c|c}
\hline \multirow{2}{*}{ Source of Variation } & \multicolumn{3}{|c|}{ Rigidity } & \multicolumn{3}{c}{ Chorea } \\
\cline { 2 - 6 } & $x^{2}$ & $\mathrm{df}$ & $\mathrm{p}$ & $x^{2}$ & $\mathrm{df}$ & $\mathrm{p}$ \\
\hline $\begin{array}{l}\text { Due to linear regres- } \\
\text { sion }\end{array}$ & 7.71 & 1 & $<0.01$ & 1.18 & 1 & $>0.2$ \\
\hline $\begin{array}{l}\text { Deviation about re- } \\
\text { gression }\end{array}$ & 0.15 & 2 & $>0.9$ & 0.68 & 3 & $>0.8$ \\
\hline Total & 7.86 & 3 & $<0.05$ & 1.86 & 4 & $>0.7$ \\
\hline
\end{tabular}

marked change in slope at early onset ages is demonstrated in Fig. 2, in which the means of equally grouped onset ages are plotted logarithmically for rigid subjects and are plotted unaltered for choreic subjects. The essential linearity of the data over the whole age range is apparent; in rigidity, $98 \%$ of the sum of squares is accounted for by linear regression. In chorea, $67 \%$ of the variation is explained by linear regression.

\section{Discussion}

The genetic factors responsible for the excess of paternal cases of early onset of Huntington's disease are not understood; Jones (1973) has suggested that potential juvenile cases succumb in utero if the mother is affected. Because rigid and choreic subjects of adult onset show no such parental bias, the effect has come to be associated with the concept of a distinct juvenile variant. Superficially, the present data could be cited to support this; paternal cases constituted $54 \%$ of rigid adults, $57 \%$ of choreic adults and $71 \%$ of children and adolescents. However, closer examination by regression analysis contradicts the idea.

The logarithmic distribution of the onset ages of rigid subjects has apparently not been noted previously. Lognormal distributions of quantitative traits were discussed by Sinnott (1937), who ascribed them to genes interacting in a multiplicative manner. Thus, if a single gene adds a definite proportion to what the rest of the genotype contributes to onset age, then the distribution will be lognormal as in rigidity. However, if a single gene adds a definite absolute proportion of the total, the distribution will be normal as in the choreic form. The elucidation of the genes producing these characteristic curves will be an important goal for future work.

The geometric mean of the onset age of persons with muscular rigidity (13.0 years with $95 \%$ confidence limits of 11.3 and 15.0 years) is appreciably lower than the value of 22 years found by Bittenbender and Quadfasel (1962) in their review of the literature. Part of the difference arises from the logarithmic transformation, the arithmetic mean of the present rigid cases being 18.0 years. The reason why subjects displaying this sign succumb at an earlier age than those with classical choreiform movements is not understood. The question is particularly intriguing when it is recalled that the respective pathological lesions appear to show no characteristic differences (Bruyn, 1969). The finding that the onset ages of rigid persons of maternal descent are later than those of paternal descent could indicate that hereditary factors are involved.

The failure by Jones and Phillips (1970) to find any parental influence on the onset ages of their subjects is probably explained by the fact that no distinction was made with respect to neurological sign. The usually high ratio of choreic to rigid persons may well have obscured any relation between the onset of rigidity and the sex of the affected parent.

The conclusion that the excess of paternal cases of early onset is the extension of a general effect throughout adulthood could have implications for classifying the forms of the disease. There would seem to be no reason for affirming the existence of a juvenile variant on genetic grounds. It may well be that clinical criteria are sufficient to establish its individuality. However, it could prove difficult to separate signs and symptoms of an authentic childhood form from those which could be modifications of the rigid or choreic variants associated with a particular stage of development of the central nervous system.

This work was supported by a grant from the National Health and Medical Research Council of Australia.

\section{REFERENCES}

Bittenbender, J. B. and Quadfasel, F. A. (1962). Rigid and akinetic forms of Huntington's chorea. Archives of Neurology, 7, 275-288. Brackenridge, C. J. (1972). Familial correlations for age at onset and age at death in Huntington's disease. Fournal of Medical Genetics, 9, 23-32.

Bruyn, G. W. (1968). Huntington's chorea. Historical, clinical, and laboratory synopsis. In Handbook of Clinical Neurology, vol. 6, ed. by P. J. Vinken and G. W. Bruyn, pp. 298-378. NorthHolland Publishing Co, Amsterdam.

Bruyn, G. W. (1969). The Westphal variant and juvenile type of Huntington's chorea. In Progress in Neuro-Genetics, vol. 1, ed. by A. Barbeau and J. R. Brunette, pp. 666-673. Excerpta Medica Foundation, Amsterdam.

Finney, D. J. (1941). On the distribution of a variate whose logarithm is normally distributed. Fournal of the Royal Statistical Society, suppl. No. 7, 155-161.

Huntington, G. (1872). On chorea. Medical and Surgical Reporter, 26, 317-321.

Jones, M. B. (1973). Fertility and age of onset in Huntington's chorea. Advances in Neurology, 1, 171-177. 
Jones, M. B. and Phillips, C. R. (1970). Affected parent and age of onset in Huntington's chorea. Fournal of Medical Genetics, 7, 20-21.

Merritt, A. D., Conneally, P. M., Rahman, N. F., and Drew, A. L. (1969). Juvenile Huntington's chorea. In Progress in NeuroGenetics, vol. 1, ed. by A. Barbeau and J. R. Brunette, pp. 645-650, Excerpta Medica, Amsterdam.
Myrianthopoulos, N. C. (1966). Huntington's chorea. Fournal of Medical Genetics, 3, 298-314.

Sinnott, E. W. (1937). The relation of gene to character in quantitative inheritance. Proceedings of the National Academy of

Sciences, 23, 224-227.
Sokal, R. R. and Rohlf, F. J. (1969). Biometry. W. H. Freeman, San Francisco.

\section{Forthcoming Symposia}

Molecular Variants in Disease. The Royal College of Pathologists is organizing a two-day symposium on molecular variants in disease to be held on Thursday and Friday 14 and 15 February 1974 . There will be sessions on 'Haemoglobinopathies' (Thursday morning); 'Inborn errors of metabolism' (Thursday afternoon); 'Erythrocyte enzyme deficiencies' (Friday morning); and 'Problems affecting the community' (Friday afternoon). There will also be papers given before the first three of these sessions on 'The genetic control of protein synthesis', 'Genetics', and 'Isoenzymes'.

Further details are available from the Royal College of Pathologists, 2 Carlton House Terrace, London SW1Y 5AF.

Preventability of Perinatal Injury. A two-day symposium on the preventability of perinatal injury will be held at the Commodore Hotel in New York City, 21-22 March 1974. Sponsored by The National Foundation-March of Dimes, the symposium programme will be presented by the Mount Sinai School of Medicine. The purpose of the two-day session will be to study in detail those forms of perinatal injury which are presently preventable. Newer approaches to the management of the perinatal period will be discussed and means for the more effective application of this knowledge will be considered.

For further information, write: Coordinator, Symposium on the Preventability of Perinatal Injury, The National Foundation-March of Dimes, 315 Park Avenue South, New York, NY 10010, USA. 